\title{
Long-term recovery of exercise capacity and pulmonary function after lobectomy
}

Yoshinori Nagamatsu, PhD, ${ }^{a}$ Kanetaka Maeshiro, MD, ${ }^{\text {a }}$ Norman Y. Kimura, MD, ${ }^{a}$ Tatsuya Nishi, MD, ${ }^{\text {a }}$ Ichirou Shima, $\mathrm{PhD}{ }^{\mathrm{b}}$ Hideaki Yamana, $\mathrm{PhD}{ }^{\mathrm{c}}$ and Kazuo Shirouzu, $\mathrm{PhD}^{\mathrm{c}}$

From the Department of Surgery, National Hospital Organization Omuta National Hospital, ${ }^{a}$ Ohmuta Fukuoka, Japan; Department of Surgery, Saiseikai Yahata General Hospital, ${ }^{\text {b }}$ Kitakyushu Fukuoka, Japan; and Department of Surgery, Kurume University, School of Medicine, ${ }^{\mathrm{c}}$ Kurume Fukuoka, Japan.

Received for publication Feb 20, 2007; revisions received June 8, 2007; accepted for publication June 14, 2007.

Address for reprints: Yoshinori Nagamatsu, $\mathrm{PhD}$, Department of Surgery, National Hospital Organization Omuta National Hospital, 1044-1 Tachibana Ohmuta City, 837-0911 Japan (E-mail: nagam2@nifty. com).

J Thorac Cardiovasc Surg 2007;134:1273-8

$0022-5223 / \$ 32.00$

Copyright $(92007$ by The American Association for Thoracic Surgery

doi:10.1016/j.jtcvs.2007.06.025
Objective: The objective of the present study was to perform longitudinal objective evaluations of recovery of exercise capacity based on expired gas analysis during exercise testing up to 1 year after pulmonary resection.

Methods: The study included 18 patients who underwent lobectomy. Expired gas analysis during exercise testing was conducted 1 week before surgery and 2 weeks, 1 month, 3 months, 6 months, and 1 year after surgery. The parameters studied included maximum exercise capacity based on expired gas analysis during exercise testing (maximum oxygen uptake per minute per square meter of body surface area) and assessment of moderate exercise capacity (anaerobic threshold per square meter of body surface area). The changes in postoperative data relative to the preoperative values (baseline) were assessed, including the percent changes from baseline data, which were arbitrarily given a value of 100 .

Results: Maximum oxygen uptake per minute per square meter of body surface area decreased significantly to $78.6 \% \pm 14.2 \%$ of the baseline value at 2 weeks after surgery and was $80.3 \% \pm 12.7 \%, 90.9 \% \pm 15.9 \%, 90 \% \pm 19.7 \%$, and $97 \% \pm 4.8 \%$ of the baseline value at 1,3 , and 6 months, and 1 year, respectively. Anaerobic threshold per square meter of body surface area reached $91.1 \% \pm 17.5 \%$ of the baseline value even 2 weeks after surgery and was $87.1 \% \pm 17.3 \%, 97.5 \% \pm$ $28.0 \%, 84.3 \% \pm 13.2 \%$, and $104 \% \pm 16.2 \%$ of the baseline value at 1,3 , and 6 months, and 1 year, respectively.

Conclusion: The extent of recovery of exercise capacity at 1 year after surgery was approximately $95 \%$. Furthermore, the anaerobic threshold per square meter of body surface area was restored to the preoperative level by 1 year after surgery.

A ccording to the annual report released by the Japanese Association for Thoracic Surgery, approximately 20,000 patients underwent surgery for lung cancer in Japan in 2003. ${ }^{1}$ The 5 -year survival after lung cancer surgery has been reported to be approximately $50 \%$ by The Japanese Joint Lung Cancer Registry Committee. ${ }^{2}$ Therefore, the number of patients with prolonged survival after pulmonary resection is increasing in Japan at a rate of approximately 10,000 per year. However, pulmonary resection causes the lung volume to decrease, thereby reducing the ventilation volume and size of the pulmonary vascular bed. These changes result in a disturbance of cardiopulmonary function and can lead to a postoperative reduction of exercise capacity. The quality of life after pulmonary resection can deteriorate partly because of such a postoperative reduction in exercise capacity. However, there have been no longitudinal studies involving the period from 2 weeks to 1 year after surgery, although there have been scattered reports on exercise capacity after pulmonary resection..$^{3-8}$ The objective of the present study was to perform a longitudinal objective evaluation of recovery of exercise capacity based on expired gas analysis during exercise testing up to 1 year after pulmonary 


\section{Abbreviations and Acronyms \\ $\mathrm{AT} / \mathrm{m}^{2}=$ anaerobic threshold per square meter \\ COPD $=$ chronic obstructive pulmonary disease \\ FEV $1.0 / \mathrm{m}^{2}$ = forced expiratory volume in 1.0 second per square meter \\ $\mathrm{FVC} / \mathrm{m}^{2}=$ forced vital capacity per square meter \\ $\% \mathrm{VC}=$ percent vital capacity \\ $\dot{\mathrm{V}}_{2} \mathrm{max} / \mathrm{m}^{2}=$ maximum oxygen uptake per minute per square meter}

resection. The long-term recovery of pulmonary function also was assessed by utilizing lung function testing, and the results were compared with those for exercise capacity.

\section{Materials and Methods}

The present study included 18 patients $(18 / 31 ; 58.1 \%)$ who had the ability to undergo sequential measurement of exercise capacity for at least 6 months after lobectomy with mediastinal lymph node dissection (R0-resection) between 1997 and 2001. Sixty-two patients with a lung mass underwent pulmonary resection or alternative treatment between 1997 and 2001 at the Department of Surgery at Saiseikai Yahata General Hospital. The surgical procedure was selected on the basis of the Institutional Criteria for the Objective Determination of Pulmonary Resection Procedures ${ }^{9}$ using a combination of preoperative cardiopulmonary function tests. Resection was not performed in 2 patients, sublobar resection was performed in 14 patients, and lobectomy without mediastinal lymph node dissection was performed in 10 patients with poor cardiopulmonary function. Bilobectomy was performed in 3 patients, and pneumonectomy was performed in 2 patients. The remaining 31 patients underwent lobectomy with mediastinal lymph node dissection (R0-resection) during the same period. Thirteen patients were excluded from this study because they could not undergo sequential measurement of exercise capacity for at least 6 months after pulmonary resection. Specifically, 1 patient had postoperative complications, 1 patient received adjuvant chemotherapy, 1 patient received adjuvant radiotherapy, 4 patients had early recurrence of primary lung cancer, 3 patients had other diseases (colon cancer, fracture of the neck of the femur, and neurosis), 2 patients did not agree to continue in this study, and 1 patient was not followed after discharge from the hospital. Seven subjects were men, and 11 subjects were women. The ages of the patients ranged from 53 to 80 years, with a mean of $70.3 \pm 7.5$ years. All patients had a favorable performance status of 0 . Fourteen patients were smokers, and 4 patients were nonsmokers. All smokers had stopped smoking for at least 4 weeks. Surgery was performed via a posterolateral thoracotomy in all patients, and lobectomy with mediastinal lymph node dissection (R0-resection) was performed in all patients. Spirometric pulmonary function test and expired gas analysis during exercise testing were conducted 1 week before surgery and 2 weeks (mean: $14.4 \pm 1.3$ days), 1 month (mean: $29.5 \pm 2.2$ days), 3 months (mean: $107.2 \pm 16.0$ days), 6 months (mean: $197.1 \pm 20.5$ days), and 1 year (mean: $388.9 \pm 45.1$ days) after surgery.
The parameters studied consisted of pulmonary function variables obtained by spirometry (forced vital capacity per square meter $\left[\mathrm{FVC} / \mathrm{m}^{2}\right]$ of body surface area, percent vital capacity [\% $\mathrm{VC}]$, forced expiratory volume in 1.0 second per square meter $\left[\mathrm{FEV} 1.0 / \mathrm{m}^{2}\right]$ of body surface area, and FEV1.0/FVC $\times 100$ ), assessment of maximum exercise capacity by expired gas analysis during exercise testing (maximum oxygen uptake per minute per square meter $\left[\dot{\mathrm{V}}_{2} \mathrm{max} / \mathrm{m}^{2}\right]$ of body surface area), and assessment of moderate exercise capacity (anaerobic threshold per square meter $\left[\mathrm{AT} / \mathrm{m}^{2}\right]$ of body surface area). The V-max System (Sensor Medics, Yorba Linda, Calif) was used for expired gas analysis. The exercise was carried out on a bicycle ergometer with a graded workload. After starting at 30 watts, the load was increased by 10 watts every 2 minutes. After reaching 60 watts, the workload was increased by 20 watts/min until a Borg rating ${ }^{10}$ of more than 16 was achieved. Expired gas analysis was performed every $20 \mathrm{sec}-$ onds. $\dot{\mathrm{V}}_{2}$ max was defined as the maximum value of $\dot{\mathrm{V}}_{2}$ during exercise, and the AT was calculated by the V-slope method. ${ }^{11}$

The changes in postoperative data from the preoperative values (baseline) were assessed, including percent changes from baseline data, which were arbitrarily given a value of 100 . Patients with a history of coronary artery disease or with ischemic changes on the electrocardiogram during the exercise test were excluded from the present study. No patients underwent preoperative radiotherapy or chemotherapy or had a history of thoracic irradiation. Patients were fully informed about the nature of this study, and all gave their informed consent for participation. There was no institutional review board in our hospital in 1997, so this study was reviewed and approved by the Department of Surgery Review Board, Saiseikai Yahata General Hospital.

\section{Statistical Analysis}

The results are expressed as the mean \pm standard deviation. Statistical analysis was performed with the StatView 5.0 computer program (SAS Institute, Inc, Cary, NC). The Student paired $t$ test was used to determine the significance of changes in the spirometric pulmonary function tests and expired gas analysis during exercise testing during the 4 periods between 2 consecutive measurements, that is, between, before, and 2 weeks after; 2 weeks after and 1 month after; 1 month after and 3 months after; 3 months after and 6 months after; and 6 months after and 1 year after surgery.

\section{Results}

The target disease was non-small cell lung cancer in all subjects. The operative procedures were divided into 4 categories: right upper lobectomy in 18 patients, right lower lobectomy in 5 patients, left upper lobectomy in 4 patients, and left lower lobectomy in 1 patient. There were no postoperative deaths or postoperative complications. According to the histologic type, tumors were divided into 2 categories: "adenocarcinoma" in 16 patients and "squamous cell carcinoma" in 2 patients. Tumors also were classified according to the postoperative histopathologic stage into 2 categories: stage I in 15 patients and stage III in 3 patients. No data for 1 year after surgery could be obtained in 1 patient because of the recurrence of lung cancer, and 3 other patients were also unavailable because they had other diseases. 
TABLE 1. Preoperative values and time course of changes in the lung function test (1)

\begin{tabular}{|c|c|c|c|c|c|c|}
\hline & Preoperative & $\begin{array}{c}2 \text { wk after } \\
\text { surgery }\end{array}$ & $\begin{array}{c}1 \text { mo after } \\
\text { surgery }\end{array}$ & $\begin{array}{c}3 \text { mo after } \\
\text { surgery }\end{array}$ & $\begin{array}{c}6 \text { mo after } \\
\text { surgery }\end{array}$ & $\begin{array}{l}1 \text { y after } \\
\text { surgery }\end{array}$ \\
\hline & & & & & & \\
\hline \multirow[t]{2}{*}{$\mathrm{FVC} / \mathrm{m}^{2}\left(\mathrm{~mL} / \mathrm{m}^{2}\right)$} & $1933 \pm 341$ & $1266 \pm 203$ & $1374 \pm 314$ & $1503 \pm 226$ & $1554 \pm 202$ & $1647 \pm 219$ \\
\hline & & & & & & \\
\hline$\%$ VC (\%) & $110 \pm 17.0$ & $67.6 \pm 12.0$ & $75.8 \pm 14.3$ & $84.3 \pm 12.4$ & $87.9 \pm 10.5$ & $93.2 \pm 12.8$ \\
\hline
\end{tabular}

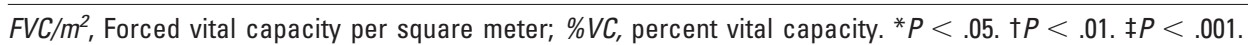

Preoperative Lung Function Testing and Expired Gas Analysis During Exercise Testing

Lung function tests were performed with satisfactory results, as shown by the mean values of $\mathrm{FVC} / \mathrm{m}^{2}, \% \mathrm{VC}$, FEV $1.0 / \mathrm{m}^{2}$, and FEV1.0/FVC $\times 100\left(1933 \pm 341 \mathrm{~mL} / \mathrm{m}^{2}\right.$, $110 \% \pm 17.0 \%, 1466 \pm 254 \mathrm{~mL} / \mathrm{m}^{2}$, and $78.7 \% \pm 6.3 \%$, respectively). Two patients had an FEV1.0/FVC $\times 100$ value of less than $70 \%$ and were regarded as having chronic obstructive pulmonary disease (COPD) according to the GOLD Scientific Committee's diagnostic criteria. ${ }^{12}$ Expired gas analysis during exercise testing showed that the mean value of $\dot{\mathrm{V}}_{2} \mathrm{max} / \mathrm{m}^{2}$ (the maximum exercise capacity parameter) was $765 \pm 192 \mathrm{~mL} / \mathrm{m}^{2}$ and that the mean value of $\mathrm{AT} / \mathrm{m}^{2}$ (the moderate exercise capacity parameter) was $516 \pm$ $137 \mathrm{~mL} / \mathrm{m}^{2}$ (Tables 1-3).

\section{Sequential Changes in Lung Function}

Among the lung function parameters studied, the $\mathrm{FVC} / \mathrm{m}^{2}$ was lower than baseline 2 weeks after surgery and had begun to recover by 1 month after surgery. The percentage of baseline was $78.5 \%$ at 3 months after surgery, $81.6 \%$ at 6 months after surgery, and only $82.7 \%$ at 1 year. In contrast, \%VC was lower than baseline 2 weeks after surgery and increased over the next 2 weeks, as did $\mathrm{FVC} / \mathrm{m}^{2}$. It had recovered further by 3 months after surgery and was $81.2 \%$ of baseline at 6 months. However, further recovery was minimal, and it was only $82.6 \%$ of baseline at 1 year. Sequential changes in the absolute $\% \mathrm{VC}$ were parallel. The FEV1.0/ $\mathrm{m}^{2}$ was lower than baseline 2 weeks after surgery, but unlike the $\mathrm{FVC} / \mathrm{m}^{2}$ and $\% \mathrm{VC}$, the $\mathrm{FEV} 1.0 / \mathrm{m}^{2}$ had not increased further 1 month after surgery. This parameter recovered by 3 months, but no further recovery was observed. The FEV $1.0 / \mathrm{m}^{2}$ was $83.6 \%$ and $82.4 \%$ of baseline at
6 months and 1 year, respectively. The absolute values reflected this sequential change. The FEV1.0/FVC $\times 100$ did not change as a result of surgery (Tables 1 and 2; Figures 1 and 2).

\section{Sequential Changes in Expired Gas Analysis During Exercise Testing}

The $\dot{\mathrm{V}}_{2} \mathrm{max} / \mathrm{m}^{2}$, a parameter of maximum exercise capacity, was lower than baseline when measured 2 weeks after surgery and showed no recovery by 1 month. However, it recovered thereafter and was $90 \%$ and $97 \%$ of baseline at 6 months and 1 year, respectively. In contrast, $\mathrm{AT} / \mathrm{m}^{2}$ (a parameter of moderate exercise capacity) was $91.1 \%$ of baseline 2 weeks after surgery and remained at this level for 1 year after surgery. All patients except 4 (1 patient with a recurrence of lung cancer and 3 other patients with unrelated medical problems) had good quality of life and performance was zero 1 year after surgery (Table 3 and Figure 3).

\section{Discussion}

Pulmonary resection involves a reduction of lung volume and causes surgical injury to the chest wall. Lung volume resection both decreases pulmonary function because of the reduced ventilation volume and increases the load on the right side of the heart because of the reduced size of the pulmonary vascular bed, resulting in a postoperative decrease of exercise capacity. Surgical injury to the chest wall and the resulting postoperative pain improve early in the postoperative course, suggesting that the impairment of lung function and exercise capacity resulting from surgical injury will resolve early. Miyoshi and colleagues ${ }^{6}$ determined changes in pulmonary function and exercise capacity

TABLE 2. Preoperative values and time course of changes in the lung function test (2)

\begin{tabular}{|c|c|c|c|c|c|c|}
\hline & Preoperative & $\begin{array}{c}2 \text { wk after } \\
\text { surgery }\end{array}$ & $\begin{array}{c}1 \text { mo after } \\
\text { surgery }\end{array}$ & $\begin{array}{c}3 \text { mo after } \\
\text { surgery }\end{array}$ & $\begin{array}{c}6 \text { mo after } \\
\text { surgery }\end{array}$ & $\begin{array}{l}1 \text { y after } \\
\text { surgery }\end{array}$ \\
\hline & & & & & & \\
\hline FEV1.0/m² $\left(\mathrm{mL} / \mathrm{m}^{2}\right)$ & $1466 \pm 254$ & $1061 \pm 198$ & $1107 \pm 193$ & $1198 \pm 185$ & $1212 \pm 169$ & $1251 \pm 135$ \\
\hline FEV1.0/FVC $\times 100(\%)$ & $78.7 \pm 6.3$ & $83.0 \pm 7.5$ & $81.9 \pm 8.6$ & $82.2 \pm 7.6$ & $79.8 \pm 7.7$ & $80.7 \pm 6.5$ \\
\hline
\end{tabular}

$\overline{F E V 1.0 / m^{2}}$, Forced expiratory volume in 1.0 second per square meter; $F V C$, forced vital capacity. ${ }^{*} P<.001$. 
TABLE 3. Preoperative values and time course of changes in expired gas analysis during exercise testing

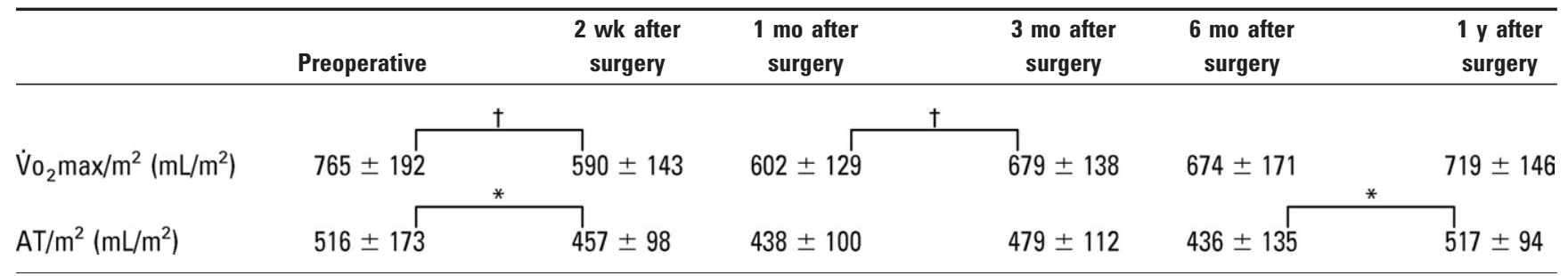

$\dot{V} 0_{2}$ max $/ m^{2}$, Maximum oxygen uptake per minute per square meter; $A T / m^{2}$, anaerobic threshold per square meter. ${ }^{*} P<.05$. $\dagger P<.001$.

during a 30-day postoperative period and concluded that early postoperative recovery is attributable to the repair of surgical injury to the chest wall and the resulting alleviation of pain. In the present study, $\mathrm{FVC} / \mathrm{m}^{2}$ and $\% \mathrm{VC}$ recovered rapidly from 2 weeks to 1 month after surgery, as in Miyoshi and colleagues' report, whereas the recovery of FEV1.0/ $\mathrm{m}^{2}$ was greater 1 to 3 months after surgery. No such change was detected in the study conducted by Miyoshi and colleagues, presumably because no further measurements were made from 1 month after surgery. As for the maximum exercise capacity, $\dot{\mathrm{V}}_{2} \mathrm{max} / \mathrm{m}^{2}$ recovered to $78.5 \%$ and $80.3 \%$ by 2 weeks and 1 month after surgery, respectively, showing a pattern similar to the findings of Miyoshi and colleagues, ${ }^{6}$ although there was a slight difference between the 2 studies in the timing of measurement. The recovery of function in the two studies in the early postoperative period is therefore considered to be largely attributable to the repair of surgical injury to the chest wall, as well as alleviation of pain. Furthermore, during the relevant period, $\mathrm{AT} / \mathrm{m}^{2}$ (a parameter of moderate exercise capacity) showed a decrease of only approximately $10 \%$, suggesting that there was little effect of surgery. Miyoshi and colleagues also measured $\dot{\mathrm{V}}_{2}$ at a venous blood lactate level of $2.2 \mathrm{mmol} / \mathrm{L}$ as a

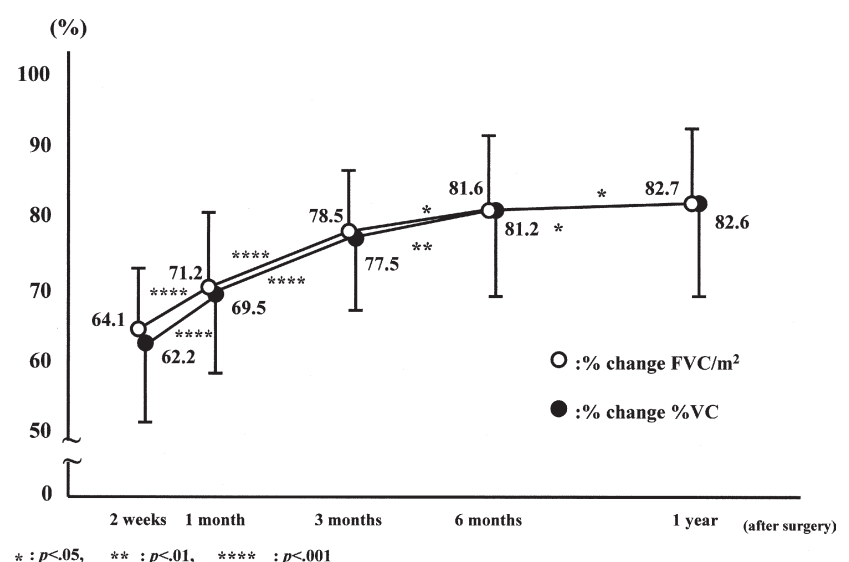

Figure 1. $\mathrm{FVC} / \mathrm{m}^{2}$ and $\% \mathrm{VC}$ improved 1 and 3 months after surgery, but there was minimal further improvement 6 months and 1 year after surgery, indicating slow recovery. $\mathrm{FVC} / \mathrm{m}^{2}$, Forced vital capacity per square meter; $\% V C$, percent vital capacity. parameter of AT. In their study, a decrease of $10 \%$ to $15 \%$ was seen early in the postoperative course, which is similar to the findings of the present study.

There have been several reports concerning the measurement of pulmonary function and exercise capacity over a long postoperative period. ${ }^{3-5,7,8}$ Bobbio and colleagues ${ }^{8}$ measured exercise capacity after lobectomy in patients with COPD and reported that the $\dot{\mathrm{V}}_{2}$ max showed a decrease of $20 \%$ from the preoperative level at 3 months after surgery. This finding differs by approximately $10 \%$ from the results of the present study. The difference probably arose because the recovery of exercise capacity after pulmonary resection was more satisfactory in the present study: The mean preoperative FEV1.0/FVC $\times 100$ value was $78.7 \%$ and COPD was diagnosed in only 2 patients by preoperative lung function testing. In contrast, Bobbio and colleagues ${ }^{8}$ studied subjects whose mean FEV1.0/FVC $\times 100$ value was $51 \%$, and all of their patients had COPD. Only 2 patients in the present study had COPD. Because the surgical procedure was selected on the basis of the Institutional Criteria for the Objective Determination of Pulmonary Resection Procedures $^{9}$ using a combination of preoperative cardiopulmo-

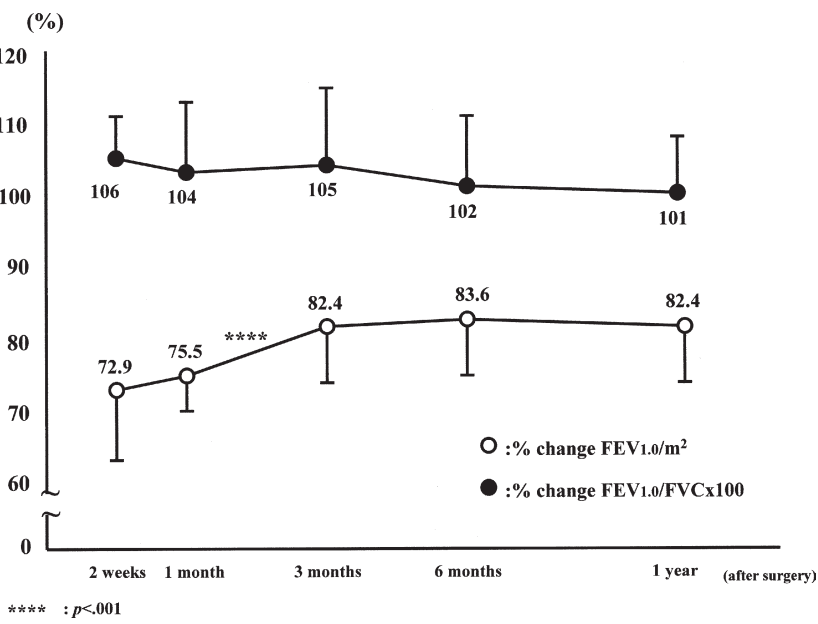

Figure 2. FEV1.0/ $\mathrm{m}^{2}$ recovered significantly 3 months after surgery. $F E V 1.0 / \mathrm{m}^{2}$, Forced expiratory volume in 1.0 second per square meter; FVC, forced vital capacity. 


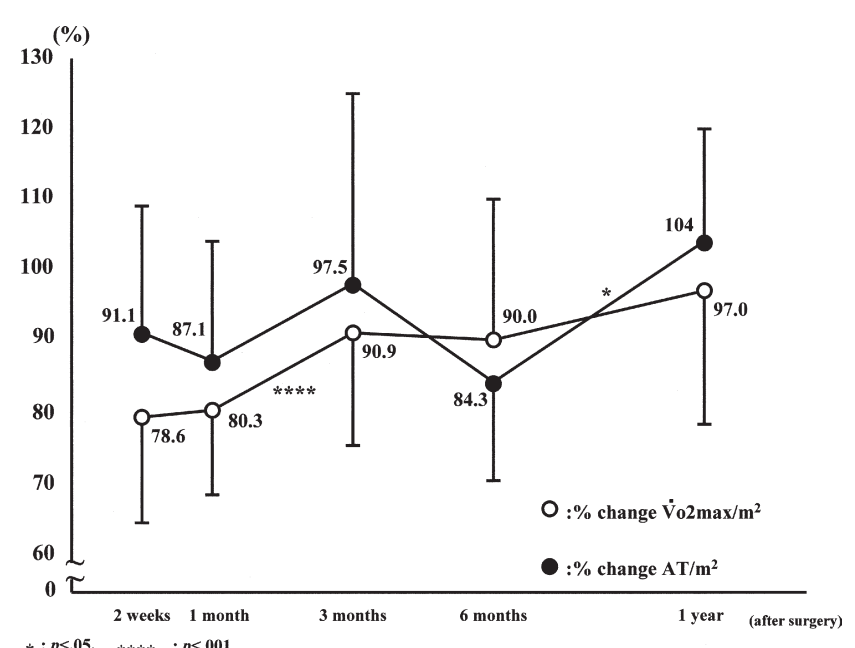

Figure 3. $\dot{V}_{0_{2}} \mathrm{max} / \mathrm{m}^{2}$ showed no significant recovery by 1 month after surgery but recovered significantly to $90.9 \% \pm 15.9 \%$ of the baseline value by 3 months after surgery and improved to $97 \% \pm$ $4.8 \%$ of the baseline value by 1 year. AT/ $\mathrm{m}^{2}$ reached $104 \% \pm$ $16.2 \%$ of the baseline value at 1 year. $\dot{V}_{2} \max / \mathrm{m}^{2}$, Maximum oxygen uptake per minute per square meter; $A T / \mathrm{m}^{2}$, anaerobic threshold per square meter.

nary function tests (FEV1.0 for the intact side $\geq 800 \mathrm{~mL} / \mathrm{m}^{2}$ by spirometry and perfusion scintigraphy, maximal oxygen uptake during exercise $\geq 650 \mathrm{~mL} / \mathrm{m}^{2}$ by expired gas analysis, and an ejection fraction $\geq 60 \%$ by echocardiography or occluded total pulmonary vascular resistance index by unilateral pulmonary artery occlusion $\leq 700$ dynes $\mathrm{cm}^{-5}$ / $\mathrm{m}^{2}$ ), patients with COPD generally received sublobar resection or lobectomy without mediastinal lymph node dissection. However, Nezu and colleagues ${ }^{5}$ measured pulmonary function and exercise capacity in patients who underwent lobectomy or pneumonectomy at 3 months and 6 months or more (mean: 10.2 months) after surgery. In the patients undergoing lobectomy, VC and FEV1.0 showed a decrease of approximately $10 \%$ at 6 months or more after surgery; thus, recovery was better in their study than in the present study. Furthermore, Nezu and colleagues ${ }^{5}$ reported that $\dot{\mathrm{V}} \mathrm{O}_{2} \mathrm{max} / \mathrm{m}^{2}$ recovered to $86.7 \%$ by 6 months or more after surgery. In contrast, the results of the present study indicate that $\mathrm{V}_{2} \mathrm{max} / \mathrm{m}^{2}$ recovered to $89.2 \%$ by 6 months after surgery, a superior outcome to that reported by Nezu and colleagues. ${ }^{5}$ This difference is considered to be due to the wide range of time (mean: 10.2 months) at which measurements were performed by Nezu and colleagues. ${ }^{5}$

In the present study, changes in lung function and exercise capacity during the first postoperative year, which had not been measured before, were determined. From 6 months to 1 year after surgery, $\mathrm{FVC} / \mathrm{m}^{2}$ improved by as little as $1.1 \%$, but FEV1.0/m $\mathrm{m}^{2}$ showed no change. In contrast, $\dot{\mathrm{V}}_{2} \mathrm{max} / \mathrm{m}^{2}$ improved by $7 \%$ during the same postoperative period, showing that the recovery of exercise capacity, unlike that of lung function, continued until 1 year after surgery. Furthermore, the extent of recovery at 1 year after surgery was approximately $80 \%$ for lung function and $95 \%$ for exercise capacity (ie, the recovery of exercise capacity was more satisfactory). In regard to $\mathrm{AT} / \mathrm{m}^{2}$, a parameter of moderate exercise capacity, this was restored to the preoperative level by 1 year after surgery. It was thus demonstrated that when the indications for surgery were appropriate, daily life after lobectomy could be similar to the preoperative state.

We draw attention to our repetition of statistical tests examining changes in the $\mathrm{FVC} / \mathrm{m}^{2}$ and other measurements in each of the pre- and postoperative periods. Repeated measures can increase the probability of obtaining a seemingly statistically significant result by chance alone, so the present results should be interpreted cautiously. However, our primary aim was to monitor changes in pulmonary parameters in specific postoperative periods, and our results were discussed within the contact of their clinical significance.

\section{Conclusions}

In the present study, lung function and exercise capacity were measured to assess postoperative recovery during the early to late postoperative period 2 weeks to 1 year after lobectomy. Lung function was shown to differ from exercise capacity with respect to the course and extent of recovery. The results obtained during the present study regarding lung function and exercise capacity can be useful when providing information on postoperative life to patients before pulmonary resection.

\section{References}

1. Kazui T, Wada H, Fujita H. Thoracic and cardiovascular surgery in Japan during 2003: annual report by The Japanese Association for Thoracic Surgery. Jpn J Thorac Cardiovasc Surg. 2005;53:517-36.

2. Goya T, Asamura H, Yoshumura H, Kato H, Shimokata K, Tsuchiya $\mathrm{R}$, et al. Prognosis of 6644 resected non-small cell lung cancers in Japan: a Japanese lung cancer registry. Lung Cancer. 2005;50:227-34.

3. Pelletier C, Lapointe L, LeBlanc. Effect of lung resection on pulmonary function and exercise capacity. Thorax. 1990;45:497-502.

4. Bolliger CT, Jordan P, Soler N, Stulz M, Wyser CT, Gonon M, et al. Pulmonary function and exercise capacity after lung resection. Eur Respir J. 1996;9:415-21.

5. Nezu K, Kushibe K, Tojo T, Takahama M, Kitamura S. Recovery and limitation of exercise capacity after lung resection for lung cancer. Chest. 1998;113:1511-6.

6. Miyoshi S, Yoshimatsu T, Hirai T, Hirai I, Maebeya S, Bessho T, et al. Exercise capacity of thoracotomy patients in the early postoperative period. Chest. 2000;118:384-90.

7. Beccaria M, Corsico A, Fulgoni P, Zoia MC, Casali L, Orlandoni G, et al. Lung cancer resection. The prediction of postsurgical outcomes should include long-term function results. Chest. 2001;120:37-42.

8. Bobbio A, Chetta A, Carbognani P, Internullo E, Verduri A, Sansebastiano $\mathrm{G}$, et al. Changes in pulmonary function test and cardiopulmonary exercise capacity in COPD patients after lobar pulmonary resection. Eur J Cardiothorac Surg. 2005;28:754-8.

9. Nagamatsu Y, Maeshiro K, Kashihara M, Iwasaki Y, Shima I, Yamana $\mathrm{H}$, et al. Selection of pulmonary resection procedures to avoid postoperative complications. Surg Today. 2007;37:202-6. 
10. Borg G. Perceived exertion as an indicator of somatic stress. Scand J Rehab Med. 1970;2:92-8.

11. Wasserman K, Whipp BJ, Koyal SN, Beaver WL. Anaerobic threshold and respiratory gas exchange during exercise. J Appl Physiol. 1973; 35:236-43.
12. Pauwels RA, Buist AS, Calverley PM, Jenkins CR, Hurd SS. GOLD scientific committee. Global strategy for the diagnosis, management, and prevention of chronic obstructive pulmonary disease. NHLBI/WHO global initiative for chronic obstructive lung disease (GOLD) workshop summary. Am J Respir Crit Care Med. 2001;163:1256-76.

\section{JTCVS On-Line Manuscript Submission and Review}

The Journal of Thoracic and Cardiovascular Surgery requires authors and reviewers to submit all new and revised manuscripts and reviews via Editorial Manager. Point your browser to http://jtcvs.editorialmanager.com, log in as author or reviewer (as appropriate), and follow the instructions provided.

To retrieve your username and password, click "Forget your password?" on the Editorial Manager log-in page.

If you have questions or experience problems uploading your manuscript or review, please contact the editorial office:

Telephone: $215-762-1854$

E-mail: jtcvs@drexelmed.edu 